\title{
Does the middle turbinate resection affect the success rate of endonasal dacryocystorhinostomy?
}

Komínek, P., Matoušek, P., Červenka, S., Pniak, T.

Clinic of Otorhinolaryngology, University Hospital Ostrava, Czech Republic

\section{Introduction}

The most common causes of failures in endonasal dacryocystorhinostomy (EDCR) are obstructions at rhinostomy. Some authors recommend using several procedures such as the silicone intubation of the lacrimal system, middle turbinate resection, and/or anterior ethmoidectomy to avoid the complications.

\section{Purpose}

To evaluate if the partial resection of the head of the middle turbinate increases a patency of the rhinostomy in the primary endonasal dacryocystorhinostomies (EDCR).

\section{Methods}

The partial middle turbinate resection is performed during EDCRs in patients with the anteriorly enlarged middle turbinate to prevent rhinostomy closure. The data were retrospectivelly collected in 630 primary EDCRs performed in the patients over 16 years old in the period 1994-2009. Only the patients with subsaccal nasolacrimal duct obstructions were involved in the study (228 cases); the patients with canalicular obstructions and secondary surgical procedures (silicone intubation, ethmoidectomy, septoplasty) were excluded. The success rates of patients with the partial middle turbinate resection (group I) and without resection (group II) were compared one year after the surgery.

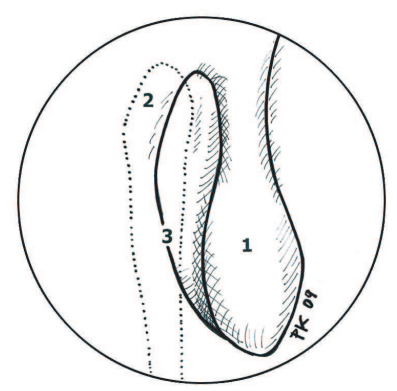

Lateral nasal wall - endonasal view: 1 - middle turbin te, 2- lacrimal sac projection, 3 - maxillary line.

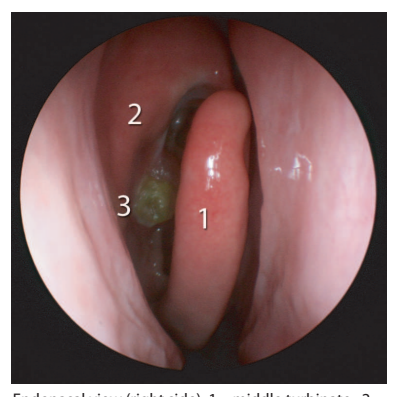

Endonasal view (right side): 1 - middle turbinate, 2 lacrimal sac projection 3 - maxillary line

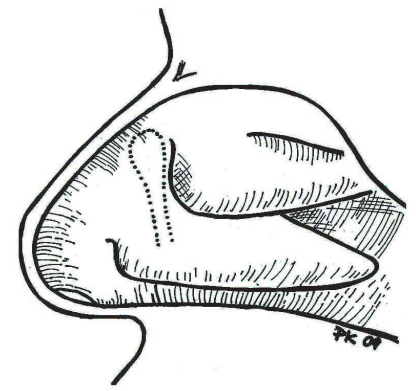

Relationship of turbinates to the nasolacrimal duct. A Anterior part or the middle concha doesn't extend anteriorly over the lacrimal sac projection. Partia concha resection is not necessary.

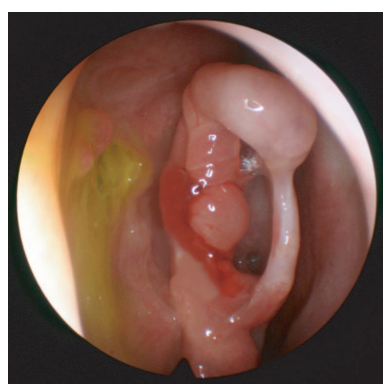

Endonasal view (right side) after EDCR with partial midlle concha resection (fluorescein flows from
rhinostomy)

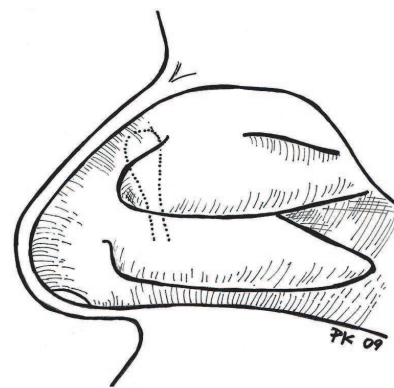

Relationship of turbinates to nasolacrimal duct. B Anterior part or the middle concha extends anteriorly, partial concha resection is recommended to prevent rhinostomy closure and scarring

Primary EDCRs - results of partial middle concha resection \begin{tabular}{|l||l|l|}
\hline EDCR/turbinate resection & mean age/years/ success rate
\end{tabular}

\begin{tabular}{l|l|l}
$\begin{array}{l}\text { group I with turbinate resection } \\
\text { (96 cases) }\end{array}$ & $16-83(51.5)$ & $94 / 96(97.9 \%)^{*}$
\end{tabular}
(96 cases)

group II without turbinate resection $\quad 16-80(55.8)$ $120 / 132(90.9 \%)$ (132 cases)

$16-83(57.9)$

$214 / 228(93.9 \%)$

\section{Results}

The overall success rate was 214/228 (93.9\%) in EDCRs with/without partial turbinate resections. In group with partial turbinate resection the success rate was $94 / 96(97.9 \%)$, in group without resection $120 / 132(90.9 \%)$. The differences between the results in groups I and II were statistically significant $(p<0,05)$.

\section{Conclusion}

The partial middle turbinate resection significantly improves the success rate in the primary EDCRs. 